\title{
Molecular Chlorambucil-Methionine Conjugate: Novel Anti-cancer Agent against Breast MCF-7 Cell Model
}

Farnoor Davachi Omoomi ${ }^{1}$, Seyed Davar Siadat ${ }^{2}$, Zahra Nourmohammadi ${ }^{1}$, Maryam Akhavan Tabasi ${ }^{1}$, Sahar Pourhoseini ${ }^{1}$, Raheleh Agha Babaei $^{4}$, Mostafa Saffari ${ }^{5}$, Mehdi Shafiee Ardestani ${ }^{3,6 *}$

${ }^{1}$ Department of Biology, Science and Research Branch, Islamic Azad University, Tehran, Iran

${ }^{2}$ Department of Microbiology, Pasteur Institute of Iran, Tehran, Iran

${ }^{3}$ Hepatitis and AIDS Department, Pasteur Institute of Iran, Tehran, Iran

${ }^{4}$ Cellular and Molecular Biology Department, School of Medicine, Islamic Azad University, Tehran, Iran

${ }^{5}$ Department of pharmaceutics, Faculty of Pharmacy, Shahid Beheshti University of Medical Sciences, Tehran, Iran

${ }^{6}$ Department of Radiopharmaceutical and Medicinal Chemistry, Faculty of Pharmacy, Tehran University of Medical Sciences, Tehran, Iran

\begin{abstract}
Breast cancer is the most common type of cancer in women worldwide and it is the second cause of cancer death after lung cancer. There have been many efforts in producing various pharmaceuticals for breast cancer treatment and among them Nanopharmaceutical Sciences have been extremely of high importance. All the drugs used to treat a cancer were usually shown unpleasant side effects. Chlorambucil is an older antineoplastic (anticancer) drug that is an alkylating agent with many known side effects for the patients. Recent findings have shown that the uptake of polyamine compounds such as amino acids (e.g. Methionine) in cancer cells is mostly increased. In this study a molecular antineoplastic conjugate, Chlorambucil-Methionine was developed and evaluated on the breast cancer MCF-7 cell line. For evaluation MTT assay, apoptosis assay and necrosis assay were employed but the mechanism of cell death or toxicity comparison were investigated by apoptosis-necrosis assay or abnormal toxicity test. Chlorambucil-Methionine as a targeted antineoplastic conjugate has shown higher antineoplastic properties and had not shown abnormal toxicity. The conjugate showed very good anticancer effects same as Chlorambucil but it had less toxicity in comparison with Chlorambucil. Apoptosis was the mechanism for most cell death in this study.
\end{abstract}

Based on the results Chlorambucil-Methionine conjugate may be a better option than Chlorambucil alone for the treatment of breast cancer. Further study is recommended to confirm these findings in clinical practice.

Keywords: Breast cancer; Chlorambucil; Methionine; Conjugate; MCF-7

\section{Introduction}

Breast cancer is the most common cancer in women worldwide. Breast cancer is second only to lung cancer in cancer deaths among women worldwide [1-5].

Many investigators have tried to develop targeted drug delivery via specific molecules to tumors. In targeted drug delivery, a certain amount of medicine can be delivered selectively to tumor cells with toxicity. In this method we used molecules that actually exist in cancerous tissues, hence there is an affinity by these tissues to absorb them [6-8].

Transfer of amino acids is necessary for growth and differentiation of normal and the transferred cells. Methionine (Met) is one of the essential and nonpolar amino acids. Methionine has antioxidant activity, and is a key factor in cell metabolism. In 2005, it was proven that there is an increased rate of transfer of certain essential amino acids in tumor cells; therefore inhibition of the carriers of these amino acids can suppress the tumor as well as the growth of tumor cells [9].

In 1997, it was shown that the growth of some solid tumors is dependent on high levels of Methionine. It was also proven the tumor cells need more Methionine compare to normal cells. It may be concluded that Methionine may be used as a selective target treatment for tumor cells [10]. Many mammalian cells as well as tumor cells have the active transport system for absorption of natural polyamine compounds. Examples of cells that have active transport for absorption of polyamine compounds include prostate tumor cells in rats, neuroblastoma, colon and lung cancer cell lines in human, and cultured cells of human lymphocytic leukemia [11].

Chlorambucil (CBL) is an alkylated anticancer drug. Chlorambucil was first synthesized by Evert in 1933. Since 1961 Chlorambucil has been used as an anticancer drug as well as an immune system suppressor agent. Chlorambucil is used for treatment of Leukemia, Hodgens and non-Hodgens lymphomas, cancer of breast, testis and ovary. Chlorambucil is also used as a reducer of immune system activity. Chlorambucil, nonspecifically affects the cell cycle by suppressing cells with a rapid rate of proliferation. Chlorambucil also causes toxicity to cells which are not in the proliferation phase. Chlorambucil acts via binding to the DNA. Chlorambucil has many side effects including nausea, vomiting, bone marrow suppression, anemia, immunosuppression, and increased risk of infection [12-14].

*Corresponding author: Mehdi Shafiee Ardestani, Department of Radiopharmaceutical and Medicinal Chemistry, Faculty of Pharmacy, Tehran University of Medical Sciences, Tehran, Hepatitis and AIDSs Department Pasteur Institute of Iran, Tehran, Iran, Tel: +98-2166953311; E-mail shafieeardestani@gmail.com

Received December 13, 2012; Accepted January 04, 2013; Published January 07, 2013

Citation: Omoomi FD, Siadat SD, Nourmohammadi Z, Tabasi MA, Pourhosein $S$, et al. (2013) Molecular Chlorambucil-Methionine Conjugate: Novel Anticancer Agent against Breast MCF-7 Cell Model. J Cancer Sci Ther 5: 075-084. doi:10.4172/1948-5956.1000188

Copyright: (c) 2013 Omoomi FD, et al. This is an open-access article distributed under the terms of the Creative Commons Attribution License, which permits unrestricted use, distribution, and reproduction in any medium, provided the original author and source are credited. 
In 1994, researchers compared the toxic effect of Chlorambucil and the conjugated Chlorambucil-Spermidine on BALB/c mice. They observed that both Chlorambucil and conjugated ChlorambucilSpermidine have toxic activity on their nervous system but conjugate Chlorambucil-Spermidine was more effective than Chlorambucil [11].

In 2004, some cyclic amidine analogs of Chlorambucil were synthesized so its cytotoxic effect on breast cancer cells as well as its inhibitory effect on topoisomerase I and II was assessed. These investigations have shown such analogs are more active than Chlorambucil [12].

In 2008, different glycoconjugated Chlorambucil compounds such as Chlorambucil-fluorodeoxyglucose hybrid were produced, and their cytotoxic effect on normal and tumor human cell lines examined in vitro. As a result, most of these conjugated compounds were more effective than nonconjugated drugs [14].

In 2010, D- and L-tyrosine-Chlorambucil analogs were synthesized and their effects as anticancer drugs on MCF-7 cell line were assessed. These analogs showed significant anticancer activities compare to Chlorambucil [6].

In 2010, Chlorambucil-estradiol hybrid was also used in breast cancer chemotherapy, and it was shown to be more effective than Chlorambucil [15].

In 2011, concerning repetitive expression of Folate Receptors (FRS) on the surface of malignant cells, researchers synthesized two new conjugates of folate with carrier Chlorambucil. Researchers then performed a biological assessment on three leukemia cell lines. The results of these experiments have shown more antitumor activities of conjugated Chlorambucil compared to nonconjugated ones [16].

The main goal in this research is production of a new anticancer conjugate of Chlorambucil-Methionine which is highly effective, and has selective targeting features, as well as the ability to prevent the growth of the breast cancer MCF-7 cell line.

\section{Materials and Methods}

In this research we investigate the steps of synthesis of ChlorambucilMethionine conjugate, its purification, culture of MCF-7 cell line and some biological tests in order to verify the effectiveness and toxic level of the mentioned conjugate.

\section{Synthesis of chlorambucil-methionine conjugate}

For synthesis of Chlorambucil-Methionine conjugate we used 5 mg Methionine (Sigma-Aldrich, USA), 2.9 mg ADH (Sigma-Aldrich, USA), $5 \mathrm{mg}$ Chlorambucil (Sigma-Aldrich, USA), $5 \mathrm{ml}$ watery solvent PBS1X (Merck, Germany), 10 mg EDC (Sigma-Aldrich, USA), 2 mg Sulfo-NHS (Sigma-Aldrich, USA), 2 ml DMSO (Merck, Germany).

Due to the sensitivity of these amidic reactions to water which is considered a solvent, we used N-hydroxy sulfo succinimide (SulfoNHS) which reduced the effect of water in the reaction hence increasing the efficiency of the reaction. ADH (adipic acid dihydrazide) was used to link Methionine to Chlorambucil. In order to increase the activity of $\mathrm{ADH}$ we used EDC which in turn increases the activity of carboxyl and results in increasing the combination carboxyl of amino acid with amine of ADH. Because Chlorambucil is lipophyllic we used DMSO which facilitates its solubility and increases the interaction rate. For synthesis, $5 \mathrm{mg}$ of Chlorambucil was added to $5 \mathrm{ml}$ of watery solvent
PBS1X. Then after 1 minute, $2 \mathrm{ml}$ of DMSO, $10 \mathrm{mg}$ EDC and $2 \mathrm{mg}$ Sulfo-NHS were added. 1 minute later $2.9 \mathrm{mg} \mathrm{ADH}$ was then added to the mixture. The solubility time duration was 5 minutes.

Methionine amino acid powder was added to $10 \mathrm{mg}$ EDC, $2 \mathrm{mg}$ Sulfo-NHS and was maintained for 5 minutes at room temperature. Next the mixture was added slowly to the previous mixture. The required time of whole synthesis was 2 hours in this experiment.

\section{Separation and purification of conjugated Chlorambucil- Methionine}

In this study, for separation and purification of ChlorambucilMethionine conjugate was used gel-filtration chromatography. For controlling the process was applied Thin Layer Chromatography (TLC) and RF of substrates and the product was calculated. Finally in order to analyze and precisely recognize the molecular structure of Chlorambucil-Methionine conjugate Liquid Chromatography Mass Spectrometry (LC/MS) (Agilent Technology (HP), UK) and H-NMR study was provided [17-19].

After synthesis process and purification of ChlorambucilMethionine, for investigating the effect of conjugate on MCF-7 cell line, MCF-7 cell line was cultured. Then with biological tests were determine the effectiveness and toxic level of Chlorambucil-Methionine conjugate.

\section{H-NMR study}

$2 \mathrm{mg}$ Chlorambucil-Methionine conjugate was dissolved in D2O and after a mild stirring at room temperature was kept in HNMR equipment (Bruker, Germany) and the conjugate HNMR spectrum was obtained.

\section{Culture of MCF-7 cell line}

For MCF-7 cell culture was used RPMI/PS/10\% FCS media. 500 $\mathrm{ml}$ of the RPMI media (Seromed Biochrom, Germany) was mixed with Penicillin/Streptomycin (P/S) with amount $100 \mathrm{U} / \mathrm{ml}$ Penicillin and $100 \mu \mathrm{g} / \mathrm{ml}$ Streptomycin. Finally were added $55 \mathrm{ml}$ fetal calf serum $(10 \%$ FCS) and then the MCF-7 cell line was cultured in it [20-23].

After MCF-7 cell line culture and reaching desired confluence (about 70\%), cell counting was done and appropriate amount of cells with media were transferred to 6 horizontal rows in a 96 well plate. Then to add Chlorambucil-Methionine conjugate, $0.1 \mathrm{mg}$ of this medicine were solved in $1 \mathrm{ml}$ DMSO and passed through 0.22 filters. The first row of 96 wells plate was selected as the positive control group and the medicine was not transferred into this row, instead at the first row we added a PHA compound which is a mitogen of cell proliferation. At the third, fourth, fifth and sixth rows, in sequence 20, 60, 120 and 240 $\mu \mathrm{L}$ of Chlorambucil-Methionine conjugate was poured. The plate was covered, the rows were marked and then it was maintained for 24 hours in an incubator at $37^{\circ} \mathrm{C}$. After 24 hours, for performing MTT test, $5 \mathrm{mg}$ of MTT (Sigma-Aldrich, USA) was dissolved at $1 \mathrm{ml}$ PBS then $20 \mu \mathrm{L}$ of the stock was added to all 6 rows. As the MTT is sensitive to light, this process was performed in darkness; the plate was covered by special foils and maintained for 4 hours in an incubator. After this time, the first row which contains the mitogen was darker than the row with no medicine which was dark purple indicating proliferation of cells. Each row with increasing medication dosage was paler and the last row was colorless indicating a high rate of cell death. Next, the whole plate was placed in a centrifuge with $300 \mathrm{~g}$ for 10 minutes in order to achieve the cellular sediment. Then the supernatants were collected from all wells and for reading OD, $100 \mu \mathrm{L}$ of DMSO was added to each well in order to dissolve the crystals. 5 minutes after adding DMSO, the plate was 
transferred to the ELISA reader (Biorad) and OD was read at $570 \mathrm{~nm}$. MTT test was done once for Chlorambucil nonconjugate with the same concentration and the result has been compared [24].

\section{Abnormal conjugate toxicity test}

For preventing non desired toxicity, all combinations should be controlled. According to specific activity of synthesized conjugate, investigating the toxicity of Chlorambucil-Methionine conjugate compared to Chlorambucil is necessary.

40 sprague-dawley rats with average weight of $90 \pm 20 \mathrm{~g}$ were selected. Due to Helsinki principals, they were treated softly and nicely. The rates were provided food, water, 12 hours of day light and 12 hours of darkness.

Animals were classified at cages. Experiment name, examiner name and the head of examination name have been written in a label to stick to the cages. The starting date and estimated ending time, animal type, weight, age and etc were also included on the label. The rats have been maintained at $21 \pm 2^{\circ} \mathrm{C}$. 7 days passed in order to allow adaptation to the situation. 4 groups of 10 were subjected to the examination. There were 5 males and 5 females in each group.

\section{Examine manner}

The type and the rate of injected medicine have been written in table 1. Transferring medicine was performed by I.P. injection and the type of measured toxicity was Acute Toxicology.

Toxicity examination has been done following these instructions:

- International committee for Harmonization of Biological compounds (ICHBC)

- Committee of proprietors of Medicinal Products (CPMP)

\section{The volume and dose of injected medicine in 2 weeks of study was as below}

The volume and dose of injected medicine in 2 weeks of study has been written in table 2 .

Animals were weighed on the first, seventh, fourteenth day of the study. After injection into all animals, they were examined once daily for symptoms of toxicity on the skin, hair and overall state of their body.

After 14 days the animals were killed by cervical dislocation method. Samples of liver, spleen and mesenteric ganglion were collected for histological study. The results of studies were compared by statistic tests like Fisher test and SPSS software.

\begin{tabular}{|c|c|}
\hline Group & Treatment \\
\hline 1 & Placebo \\
\hline 2 & $120 \mu \mathrm{g}$ Chlorambucil \\
\hline 3 & $60 \mu \mathrm{g}$ Chlorambucil-Methionine \\
\hline 4 & $120 \mu \mathrm{g}$ Chlorambucil-Methionine \\
\hline
\end{tabular}

Table 1: The type and the rate of injected medicine.

\begin{tabular}{|c|c|c|c|c|}
\hline \multirow{2}{*}{ Group } & \multirow{2}{*}{ Male } & \multirow{2}{*}{ Dose $(\mu \mathrm{g} / \mathrm{kg})$} & \multicolumn{2}{|c|}{ Volume administered $(\mu \mathrm{l})$} \\
\cline { 3 - 5 } & & & Male & Female \\
\hline 1 & 10 & - & 230 & 200 \\
\hline 2 & 10 & 1000 & 80 & 70 \\
\hline 3 & 10 & 500 & 150 & 140 \\
\hline 4 & 10 & 1000 & 230 & 200 \\
\hline
\end{tabular}

Table 2: The volume and the dose of injected medicine in 2 weeks.

\section{Investigating of medicine toxicity by apoptosis assay and necrosis assay on cells}

TNF- $\alpha$ testing for investigating necrosis on MCF-7 cell line: To perform this study the Raybio ${ }^{\circledR}$ Human TNF- $\alpha$ ELISA kit was used. This kit is used for measuring the human TNF- $\alpha$ in serum, plasma, supernatants for cell culture and urine. This assay employs an antibody specific for human TNF- $\alpha$ coated on a 96-well plate. Standards and samples were pipetted into the wells and TNF- $\alpha$ present in a sample was bound to the wells by the immobilized antibody. The wells were washed and biotinylated anti-human TNF- $\alpha$ antibody was added. After washing away unbound biotinylated antibody, HRP-conjugated streptavidin was pipetted to the wells. The wells were again washed, a TMB substrate solution was added to the wells and color developed in proportion to the amount of TNF- $\alpha$ bound. The Stop Solution changed the color from blue to yellow, and the intensity of the color was measured at $450 \mathrm{~nm}$.

First, MCF-7 cell line was incubated with the $120 \mu \mathrm{M}$ and $240 \mu \mathrm{M}$ concentrated Chlorambucil and Chlorambucil-Methionine conjugate. Cells were precipitated by centrifuges. The supernatants were collected and used for measuring the TNF- $\alpha$ secreted which due to a special protocol was read at $450 \mathrm{~nm}$ with microplate reader. The negative control included only 1640-RPMI.

\section{Apoptosis assay on MCF-7 cell line}

Apoptosis and necrosis cells were identified using AnnexinV-PI (PI: propidium iodine) coloring kit (BD Pharmingen, UK). After MCF7 cell line culture beside the Chlorambucil-Methionine conjugate at the highest medicine dose $(240 \mu \mathrm{M})$ for 24 hours at incubator, it was washed three times by PBS then trypsin was added and transferred to a new tube. The cells were precipitated in a centrifuge for 5 minutes with $200 \mathrm{~g}$. Then cells were colored by trypan blue (Sigma-Aldrich, USA) and then were counted. About $10^{6}$ cells were separated for flow cytometry. Cells (including treated or non treated cells) with buffering AnnexinVPI have been maintained for 15 minutes at room temperature. Then they were incubated with $500 \mu \mathrm{l}$ buffering and diluted for flow cytometry. The percent of Apoptotic and necrotic treated cells compared to the untreated control group or compared to treated Chlorambucil non conjugate cells (with doses 60 and $100 \mu \mathrm{g} / \mathrm{ml}$ ) by flow cytometry (FCAS Calibur, BD) with WinMDI 2.9 version at excited wavelength and proper distribution (excitation wavelength at $488 \mathrm{~nm}$ and distribution at $518 \mathrm{~nm}$ for AnnexinV recognition) were determined according to suggested protocols for tracing kit at FITC-PI [20,25].

\section{Blood cell hemolysis}

In order to investigate the blood cell hemolysis by the ChlorambucilMethionine conjugate, blood samples of selected rats (health controlled with no drug injected) have been collected. To prevent clotting, sodium citrate (Sigma-Aldrich, USA) 3.2\% was added. Complete blood was centrifuged for 5 minutes at room temperature with 1000 rpm in order separate plasma without placket. Supernatants were discarded and washed three times with cool PBS. Then Chlorambucil and conjugate Chlorambucil-Methionine conjugate were dissolved in PBS/DMSO and were incubated for 6 hours with a blood sample mix consist of Chlorambucil or Chlorambucil-Methionine and blood with ratio 5:1 volumetric/volumetric at $37^{\circ} \mathrm{C}$. After centrifuging for 5 minutes at $1000 \mathrm{rpm}$ and collecting supernatants it was read at $413 \mathrm{~nm}$ by spectrophotometer (Shimatzo, Japan) and results were compared 
to positive control $(0.1 \% \mathrm{v} / \mathrm{v}$ Triton-X100 in PBS that reveals $100 \%$ hemolysis) [26].

Investigating the blood coagulation factors in exposed the conjugate Chlorambucil-Methionine:

In this study the rate of blood coagulation factors was investigated for exposed the Chlorambucil-Methionine conjugate. For this method, $2 \mathrm{ml}$ of selected rats' blood was phlebotomized and mixed with Chlorambucil-Methionine and the coagulation time was compared with control group.

\begin{tabular}{|c|c|c|c|c|c|c|}
\hline Material & Methionine & ADH & Sulfo-NHS & CBL-Met & CBL & EDC \\
\hline $\mathrm{Rf}$ & 0.72 & 0.82 & 0.49 & 0.40 & 0.32 & 0.88 \\
\hline
\end{tabular}

Table 3: Rf values-calculated from TLC paper, the distance passed by the mentioned material into the distance passed by the solvent.

Manufacturer Company: Agilent Technology (HP)

1. MS Model: 5973 Network Mass Selective Detector

2. Ion source: Electron Impact (EI) $70 \mathrm{eV}$

3. Ion source temperature: $230^{\circ} \mathrm{C}$

4. Analyzer: Quadrupole

5. Analyzer temperature: $150^{\circ} \mathrm{C}$

Table 4: Instrument Specifications of mass spectroscopy

\begin{tabular}{|c|c|c|c|c|c|}
\hline Parameter & Step 1 & Step 2 & Step 3 & Step 4 & Step 5 \\
\hline Initial Temperature $\left({ }^{\circ} \mathrm{C}\right)$ & 50 & --- & --- & --- & -- \\
\hline Initial Time $(\mathrm{min})$ & 0 & --- & --- & --- & --- \\
\hline Program Rate $\left({ }^{\circ} \mathrm{C} / \mathrm{min}\right)$ & 80 & --- & --- & --- & --- \\
\hline Final Temperature $\left({ }^{\circ} \mathrm{C}\right)$ & 350 & --- & --- & --- & --- \\
\hline Final Time $(\mathrm{min})$ & 5 & --- & --- & --- & --- \\
\hline
\end{tabular}

Table 5: Condition and specification of mass spectroscopy.

\section{Results}

Results of separation and purification of synthesized Chlorambucil-Methionine conjugate by gel-filtration chromatography and thin layer chromatography (TLC)

In gel-filtration chromatography, the solution was subjected to the chromatography column and collected into 20 tubes. Each tube contained $1 \mathrm{ml}$ or 20 drops of solution. Next every tube was studied with TLC to study for existence of products. Then the spots were analyzed by UV lamp. The existence of the product was recognized in tubes s four to seven. The Rf of each combination was calculated in table 3.

\section{Results of mass spectroscopy}

For accurate analysis of molecular structure and ChlorambucilMethionine conjugate recognition, mass spectroscopy LC/MC (Liquid Chromatography Mass Spectrometry) has been used.

The Instrument Specifications, condition and specification of mass spectroscopy are in tables 4 and 5 .

Despite the molecular weight of the conjugate in mass spectroscopy interpretation $(\mathrm{MW}=590.22)$ and the existence of 3 to 4 breaks in figure 1 , the molecular structure of Chlorambucil-Methionine conjugate has been confirmed.

\section{Results of H-NMR study}

According to figure 2, peaks regarding aromatic rings of Chlorambucil as well as $\mathrm{ADH}, \mathrm{CH} 3, \mathrm{CH} 2$ of the amino acid and Chlorambucil are obviously observed.

Results of toxicity measurement of Chlorambucil and Chlorambucil-Methionine conjugate on MCF-7 cell line by MTT assay

This is a colorimetric assay that measures the ability of living cells to

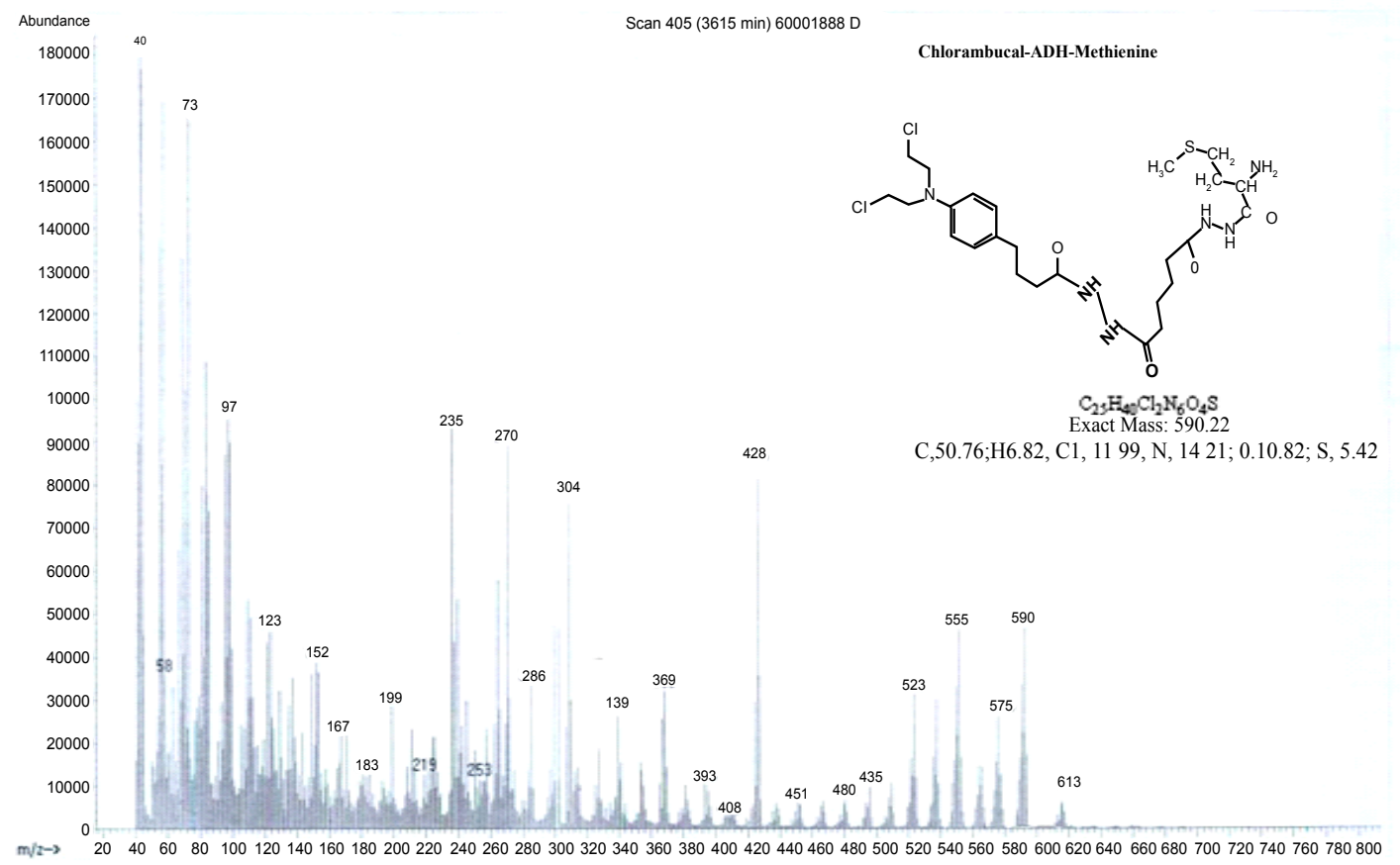

Figure 1: Mass spectroscopy diagram of Chlorambucil-Methionine conjugate with LC/MC apparatus. 


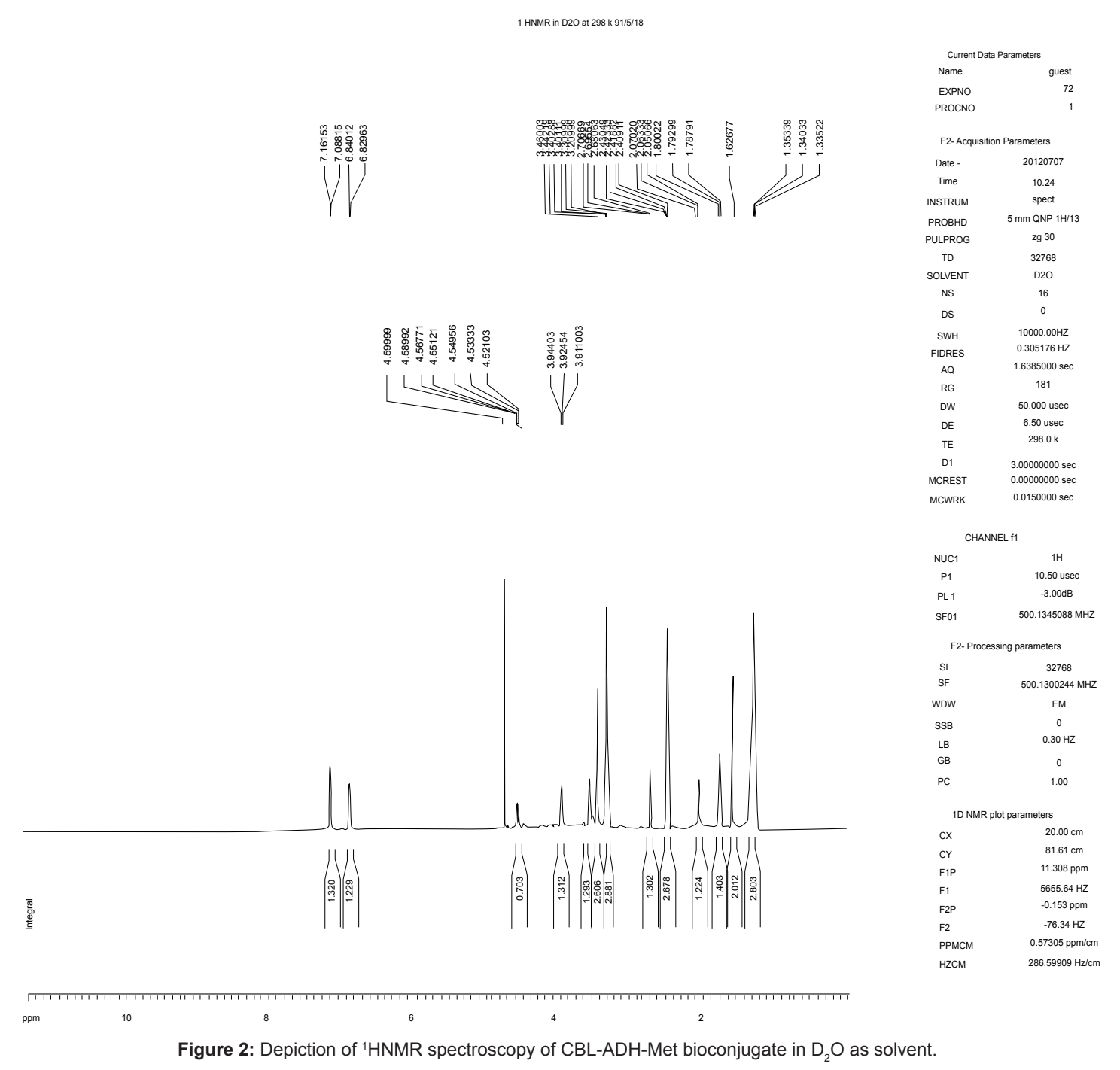

convert tetrazolium salt solution MTT which is yellow into Formozan an insoluble material which is purple. The dark color is a sign of the existence of more living cells. By this method, the cells viability with the non conjugate Chlorambucil and Chlorambucil-Methionine conjugate with different doses was studied.

\section{Results of the toxicity of Chlorambucil on MCF-7 cell line by MTT assay}

In plate well 96, cultured cells of MCF-7 cell line were exposed to Chlorambucil. The first row of wells was not exposed to Chlorambucil and is considered the control group. The second row was exposed to $20 \mu \mathrm{M}$ of Chlorambucil, the third row $60 \mu \mathrm{M}$ of Chlorambucil, the fourth row $120 \mu \mathrm{M}$ and the fifth row $240 \mu \mathrm{M}$ of Chlorambucil. After 24 hours, the MTT test was done and OD was read at $570 \mathrm{~nm}$ wavelength. Diagrams were traced based on, in order to make the diagram linear and acceptable; the diagrams were calculated as the percentage of living cells with respect to the drug dose (Figures 3 and 4).

The formula which was used for measuring the living cells percentage is as follows:

In order to investigate the existence or lack of significant difference in drug doses of the statistical point of view, SPSS16, One way ANOVA and Post hoc test Tukey software was used.

Measurements by One way Anova showed that, the percentage of living cells with different doses of Chlorambucil were as follows:

- No significant difference was observed between control group and $20 \mu \mathrm{M}$ Chlorambucil.

- A significant difference of $\mathrm{p}<0.05$ was observed between the control group and $60 \mu \mathrm{M}$ Chlorambucil.

- A significant difference of $p<0.01$ was observed between the control group and $120 \mu \mathrm{M}$ Chlorambucil.

- A significant difference of $\mathrm{p}<0.001$ was observed between the control group and $240 \mu \mathrm{M}$ Chlorambucil.

\section{Results of toxicity measurement of Chlorambucil-Methionine on MCF-7 cell line by MTT assay}

MCF-7 cell line was placed in 96 wells plate and exposed to Chlorambucil-Methionine conjugate. The first row of wells contained 


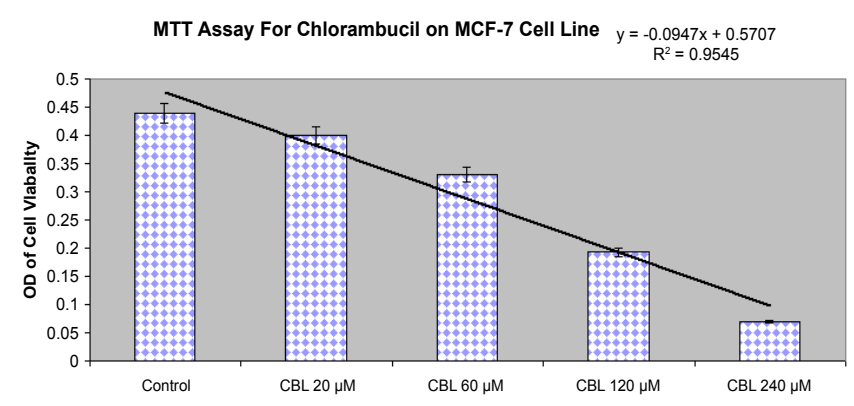

Figure 3: Results of MTT assay of different Chlorambucil doses on MCF-7 cell according to OD of living cells.

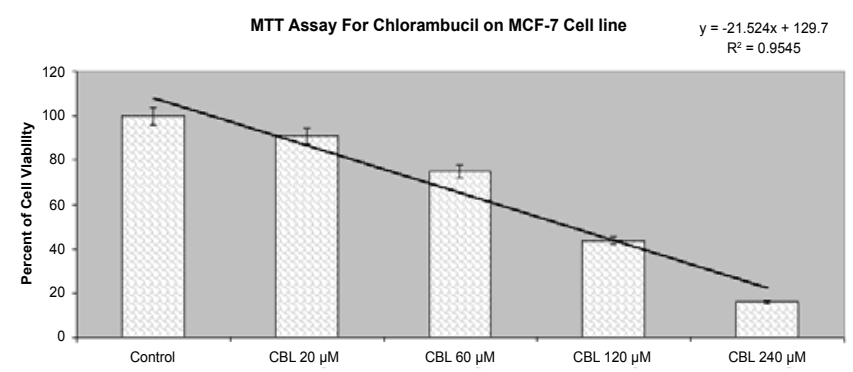

Figure 4: Results of MTT assay of different Chlorambucil doses on MCF-7 cell according to percent of living cells.

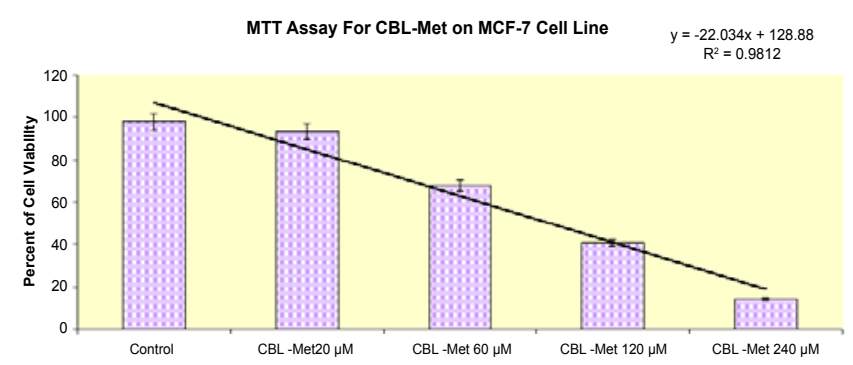

Figure 5: Results of MTT assay of different Chlorambucil- Methionine doses on MCF-7 cell line according to the percentage of living cells.

no drug and was considered the control group. In second, third, fourth and fifth rows $20,60,120$ and $240 \mu \mathrm{M}$ of Chlorambucil-Methionine conjugate was added. After 24 hours a MTT test was completed and OD was read at $570 \mathrm{~nm}$ wavelength. All diagrams have been traced based on and in order to make the diagram linear and acceptable, they were traced as the percentage of living cells with respect to the drug dose.

According to the measurement by One way Anova, the percentage of living cells with different doses of Chlorambucil-Methionine (CBLMet) was as follows:

- No significant difference was observed between the control group and $20 \mu \mathrm{M}$ dose of Chlorambucil-Methionine.

- A significant difference of $\mathrm{p}<0.05$ was observed between control group and $60 \mu \mathrm{M}$ dose of Chlorambucil-Methionine.

- A significant difference of $\mathrm{p}<0.01$ was observed between control group and $120 \mu \mathrm{M}$ dose of Chlorambucil-Methionine.

- A significant difference of $\mathrm{p}<0.001$ was observed between control group and $240 \mu \mathrm{M}$ dose of ChlorambucilMethionine.

According to figures 4 and 5 (percentage of living cells in different concentration of Chlorambucil and Chlorambucil-Methionine), with the addition of drug dose, cell death was increased and the percentage of living cells decreased which indicates the Chlorambucil-Methionine conjugate maintained its anti-cancer properties.

\section{EC50 calculation in linear model diagram}

EC50 is a drug dose in which 50 percent of the cells are killed. For tracing this diagram, MCF-7 living cell line percentages in different doses were considered.

According to the formula, $y$ is equal to 50 (which mean $50 \%$ of cells are living) and the EC50 of Chlorambucil on MCF-7 cell line is equal to $138.273 \mu \mathrm{M}$.

EC50 of Chlorambucil-Methionine conjugate on MCF-7 cell line is equal to $120.535 \mu \mathrm{M}$. According to figures 6 and 7 and the slope of the line in these diagrams, EC50 of Chlorambucil was 138.273 $\mu \mathrm{M}$ and EC50 of Chlorambucil-Methionine conjugate was $120.535 \mu \mathrm{M}$. Comparing these two values shows the Chlorambucil-Methionine property of cell

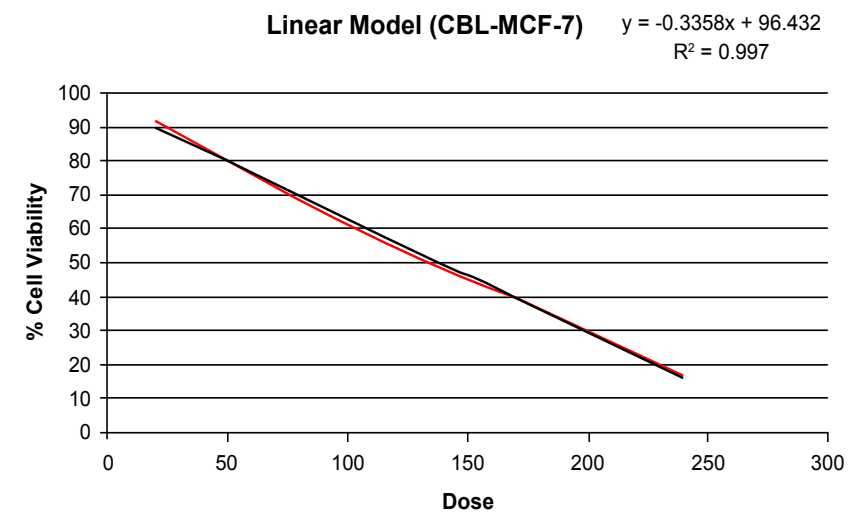

$y=0.3358 x+96.432$

If $y=50, x=E C 50$

$50=0.3358 x+96.432$

$-46.432=0.3358 x$

$\mathrm{X}=\mathrm{CBL}-\mathrm{EC} 50=138.273 \mu \mathrm{M}$

Figure 6: EC50 Linear Model, effect of Chlorambucil on MCF-7 cell.

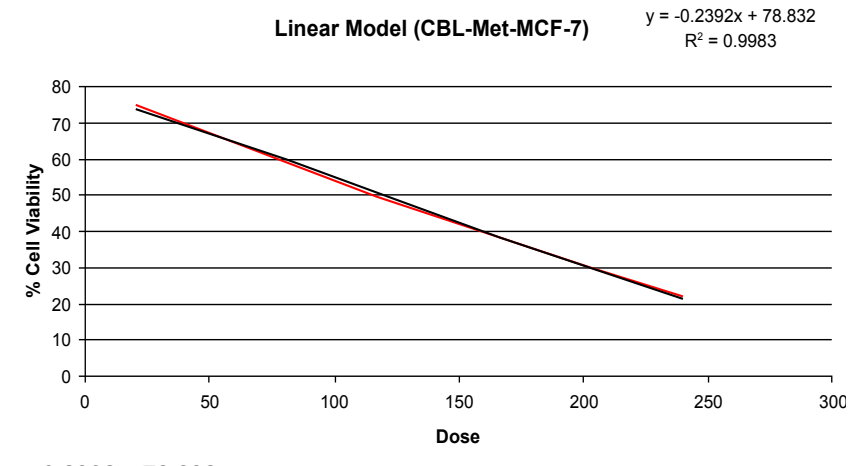

$y=0.2392 x+78.832$

$X=C B L-M e t-E C 50=120.535 \mu \mathrm{M}$

Figure 7: EC50 Linear Model, effect of Chlorambucil-Methionine on MCF-7 cell. 


\begin{tabular}{|c|c|c|c|}
\hline Group & Day 1 Weight(g) & Day 7 Weight(g) & Day 14 Weight(g) \\
\hline 1 & $90.5 \pm 4.12$ & $133.3 \pm 6.23$ & $149.7 \pm 5.35$ \\
\hline 2 & $91.2 \pm 4.87$ & $132.7 \pm 5.11$ & $150.2 \pm 6.88$ \\
\hline 3 & $90.8 \pm 5.12$ & $138.8 \pm 8.42$ & $151.3 \pm 5.21$ \\
\hline 4 & $90.3 \pm 5.73$ & $135.3 \pm 9.21$ & $147.2 \pm 4.74$ \\
\hline
\end{tabular}

Table 6: Results of weight in examined female mouse.

\begin{tabular}{|c|c|c|c|}
\hline Group & Day 1 Weight(g) & Day 7 Weight(g) & Day 14 Weight(g) \\
\hline 1 & $100.4 \pm 3.36$ & $149.2 \pm 6.80$ & $197.9 \pm 12.32$ \\
\hline 2 & $101.2 \pm 2.93$ & $142.4 \pm 5.56$ & $165.3 \pm 18.24$ \\
\hline 3 & $100.9 \pm 2.76$ & $157 \pm 3.49$ & $196.6 \pm 6.83$ \\
\hline 4 & $101.1 \pm 3.43$ & $148 \pm 7.39$ & $163.4 \pm 9.92$ \\
\hline
\end{tabular}

Table 7: Results of weight in examined male mouse.

death at low concentrations in front of the cell death of non conjugate Chlorambucil. In other words with increasing drug concentration, cell death increases and it can be concluded that Chlorambucil-Methionine conjugate has stronger anti-cancer property compared to non conjugate Chlorambucil.

\section{Abnormal toxicity measurement test of conjugate}

The volume and dose of the injected Chlorambucil-Methionine conjugate in two weeks and animal weight in first, seventh and fourteenth day are shown in the tables 6 and 7 .

- According to tables $1,2,6,7$ the process of gaining weight in animals in 2 weeks was normal and no clear difference was observed with similar doses and with injected drugs. Based on this data it appears that Chlorambucil and ChlorambucilMethionine conjugate have no effect on the process of weight gain in mice.

- According to these data and observations, no lab macroscopic damage was observed for Chlorambucil-Methionine despite one female mouse death with the $120 \mu \mathrm{g}$ dose of ChlorambucilMethionine and Chlorambucil caused 2 female mouse deaths and one male mouse death.

\section{Results of toxicity measurement of Chlorambucil-Methionine by apoptosis assay and necrosis assay on MCF-7 cell line}

Results of TNF- $\alpha$ release test: After incubation of the MCF-7 cell line for 24 hours with 120 and $240 \mu \mathrm{M}$ Chlorambucil and ChlorambucilMethionine conjugate, cells were precipitated by centrifuges and the supernatant was collected and used for determining secreted TNF- $\alpha$. Based on a special protocol OD has been read at $450 \mathrm{~nm}$ wavelength by a microplate reader. The negative control group includes only 1640 RPMI.

Calibration curve by TNF- $\alpha$ was drawn. Sample OD was divided by control group OD and results are shown based on percentage in the diagram.

According to figure 8 in diagram:

- A significant difference of $\mathrm{p}<0.05$ was observed $120 \mu \mathrm{M}$ dose of Chlorambucil and Chlorambucil-Methionine.

- A significant difference of $\mathrm{p}<0.05$ was observed $240 \mu \mathrm{M}$ dose of Chlorambucil and Chlorambucil-Methionine.

This diagram shows that for all Chlorambucil and ChlorambucilMethionine concentrations, induced secretion property of TNF- $\alpha$ of Chlorambucil was more than for Chlorambucil-Methionine.
Apoptosis test results on MCF-7 cell line: Chlorambucil dose and Chlorambucil-Methionine doses were constant. The $240 \mu \mathrm{M}$ was considered the appropriate dose because apoptosis phenomenon is non-recognizable at lower doses. A control group was also considered.

According to figure 9, in diagrams;

- At time zero, apoptosis increasing was not significant. Between 12 and 24 hours treated Chlorambucil and ChlorambucilMethionine conjugate showed no significant but a significant difference was observed between time zero and 24 hours in the treated sample.

- The diagram shows that in same concentration $(240 \mu \mathrm{M})$ Chlorambucil and Chlorambucil-Methionine, the apoptosis property of Chlorambucil-Methionine conjugate was more than Chlorambucil.

TNF-alpha Assay
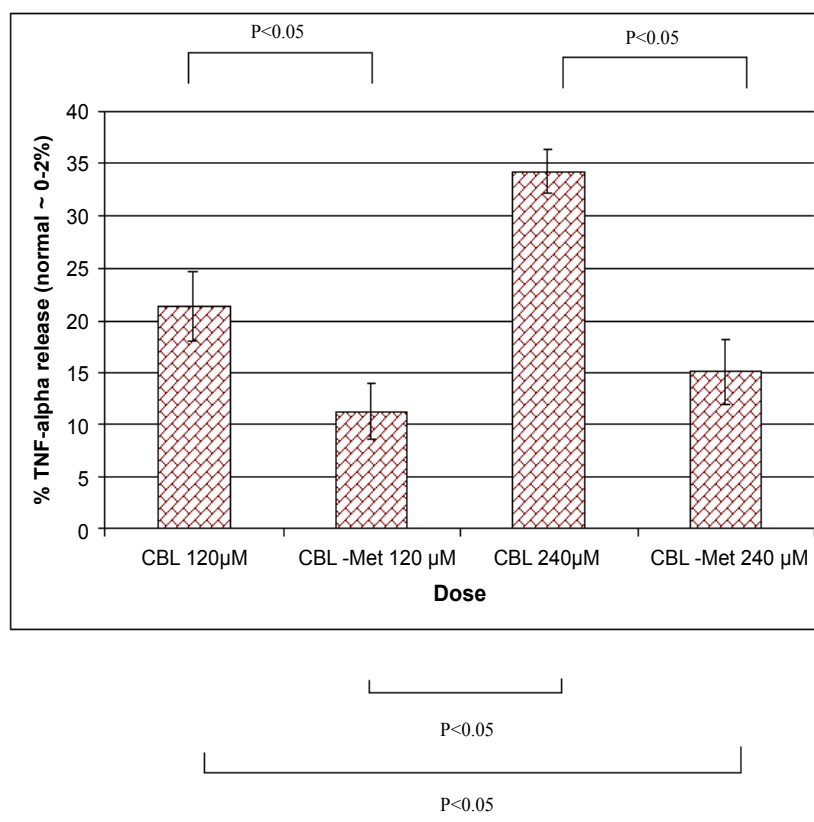

Figure 8: Results of release TNF- $\alpha$ test.
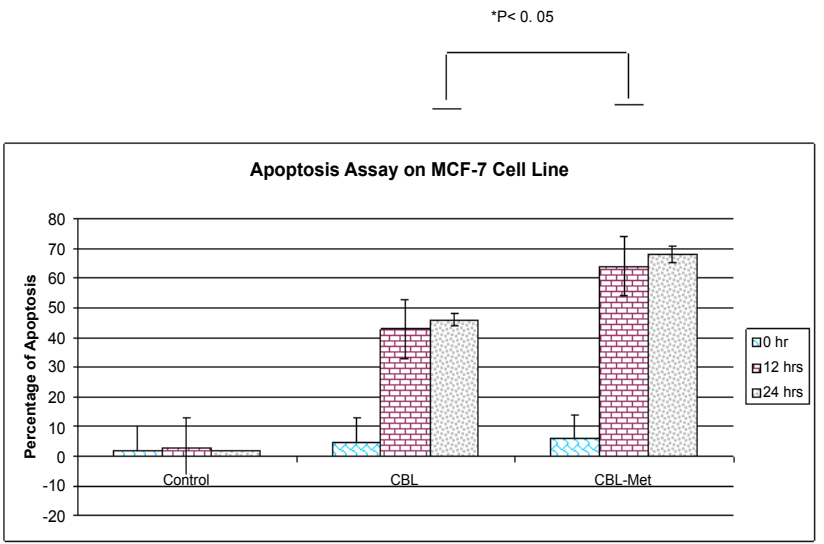

Figure 9: Results of apoptosis test on MCF-7 cell at $240 \mu \mathrm{M}$ drug dose. 


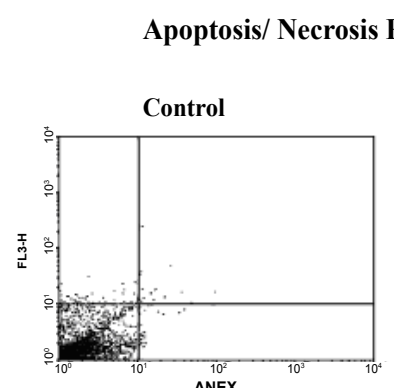

(a)

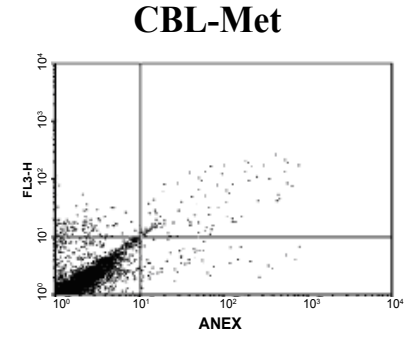

(b)

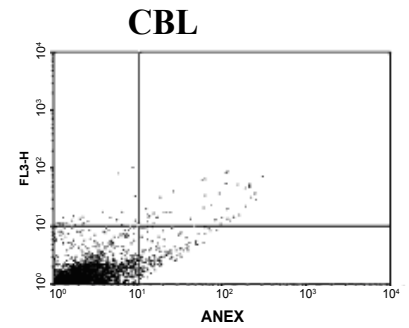

(C)

Figure 10: Comparison of apoptosis and necrosis diagram after MCF-7 cell line was exposed to Chlorambucil and Chlorambucil-Methionine for 24 hours:

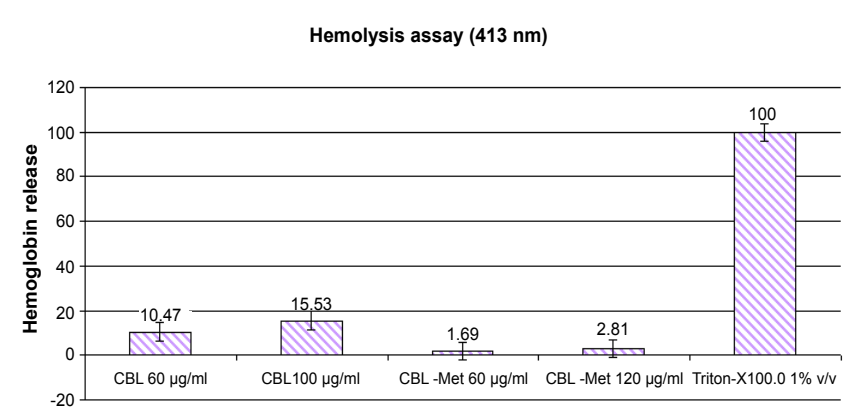

Figure 11: Results of blood cell hemolysis at different concentrations of Chlorambucil and Chlorambucil-Methionine.

- To increase the accuracy of results, a comparison by T-Test was made between Chlorambucil and Chlorambucil-Methionine. Also, one way ANOVA at identical time was used as a comparison method between the control group, Chlorambucil and Chlorambucil-Methionine.

- By comparison of necrosis and apoptosis, diagrams concluded that the Chlorambucil-Methionine conjugate induces more cell death than the apoptosis assay.

Comparison of apoptosis and necrosis diagram after MCF7 cell line was exposed to Chlorambucil and ChlorambucilMethionine for 24 hours

Comparison of apoptosis and necrosis diagram after MCF-7 cell line was exposed to Chlorambucil and Chlorambucil-Methionine for 24 hours has been shown on figure 10 .

\section{Results of blood cell hemolysis}

- In figure 11 , positive control group $(0.1 \% \mathrm{v} / \mathrm{v}$ Triton-X100 in PBS) shows $100 \%$ hemolysis.
- Based on these results, no significant effect of hemolysis at 60 $\mu \mathrm{g} / \mathrm{ml}$ and $120 \mu \mathrm{g} / \mathrm{ml}$ Chlorambucil-Methionine was observed. Based on the fact that the most of the anti-cancer drugs cause blood cell hemolysis resulting in anemia in patients, production of an anti-cancer drug which does not cause hemolysis is important.

- For $60 \mu \mathrm{g} / \mathrm{ml}$ and $100 \mu \mathrm{g} / \mathrm{ml}$ Chlorambucil, blood cell hemolysis was observed and the hemolysis rate was more prominent at $100 \mu \mathrm{g} / \mathrm{ml}$ Chlorambucil, about $15.53 \%$ compared to the positive control group.

\section{Analyzing blood coagulation factors with Chlorambucil- Methionine conjugate}

$2 \mathrm{ml}$ of blood was placed with the Chlorambucil-Methionine and time of coagulation was compared to the control group. Both groups show identical time to coagulation which shows that the conjugate is not effective on blood coagulation. Based on achieved results from blood hemolysis step, this result was predictable.

\section{Discussion}

Synthesis of targeted drugs is essential for cancer treatment. Use of untargeted anticancer drugs has many side effects for the patients.

Chlorambucil is an alkylating agent and has been used as an anticancer drug for many years. It has a nonspecific effect on cells and its mechanism of action is not well known. Because of its nonspecific action, Chlorambucil has many complications when used as an anticancer treatment.

The goal of the synthesis of the molecular conjugate of ChlorambucilMethionine was to find an anticancer drug which works in a targeted manner. The cell killing ability of Chlorambucil-Methionine conjugate on breast cancer MCF-7 cell line was more than Chlorambucil, when used in similar doses.

Concerning to the EC50 results, Chlorambucil-Methionine conjugate had a lower EC50 compared to Chlorambucil. The EC50 of Chlorambucil-Methionine conjugate indicates that Chlorambucil-Methionine conjugate results in higher cell killing at lower concentrations than Chlorambucil. Because lower doses of Chlorambucil-Methionine conjugate are needed fewer side effects are observed. Chlorambucil-Methionine conjugated induces cell death mostly via apoptosis. $15.53 \%$ of patients on Chlorambucil showed hemolysis, but the Chlorambucil-Methionine conjugate did not show evidence of red blood cell hemolysis.

The following is concluded based on the experiments comparing Chlorambucil to Chlorambucil-Methionine conjugate:

- Binding of the amino acid Methionine to Chlorambucil did not reduce the anticancer effect of Chlorambucil, and actually increased the anticancer ability above Chlorambucil alone.

- Due to the avidity of cancerous cells in absorption of polyamine compounds, the binding of Methionine to Chlorambucil is a targeted compound which will be absorbed in a higher rate by cancerous cells.

In 2004, Buchrach and colleagues investigations on polyamines and cancer showed there is an increased accumulation of polyamine compounds in cancerous tissues. The concentration of polyamine compounds is also high in body fluids of cancerous patients [27].

In 2005, Yoon and colleagues realized that the transfer of some 
essential amino acids increases in cancerous cells. Because cancerous cells have a high metabolism, the absorption of amino acids is also increased in cancerous cells. Using drugs with ability to reduce polyamine synthesis and/or blocking carriers of these amino acids may be a better option in cancer treatment [9].

In 2009, Palmer and his colleagues declared that increased concentration of polyamines has an important role in cancer progression, from the beginning stage to the maintenance of transform phenotype [8].

One of the mechanisms in which cancerous cells increase the accumulation of polyamine compounds is the absorption of polyamines via a system called PTS "Polyamine Transport System". PTS is a nonselective system which transports a wide spectrum of polyamines; therefore it is possible to transfer the cytotoxic drugs after binding them to the polyamine vectors and selectively aim the cancerous cells via this system [9].

In 1997, the growth dependency of some solid tumors on high levels of Methionine was proven. It was also shown that tumor cells need increased levels of Methionine compared to normal cells. These findings indicate that Methionine can be selected as an appropriate option for the treatment of tumors [10].

Chlorambucil-Methionine conjugate is considered a polyamine compound. Because Chlorambucil-Methionine conjugate has high levels of nitrogen in its chemical structure and contains the amino acid Methionine it is absorption by cancerous cells is increased.

Utilizing transport carriers and synthesis of drug conjugates allows anticancer treatments to be more selective and specific.

Since Chlorambucil is a nonspecific anticancer drug with several side effects, many efforts have been made for synthesis of conjugated Chlorambucil as a targeted drug with fewer side effects.

In 1992, Holley and colleagues synthesized the ChlorambucilSpermidine conjugate, considering that polyamines have a high affinity for binding to DNA, enabling Chlorambucil-Spermidine to target the DNA more efficiently and effectively [28].

In 1994, the researchers synthesized Chlorambucil-Spermidine conjugate and compared the toxicity of Chlorambucil-Spermidine to Chlorambucil on $\mathrm{BALB} / \mathrm{c}$ mice, and it was shown that both drugs had toxicity on the central nervous system of the mice, but the ChlorambucilSpermidine conjugate was more effective than the Chlorambucil [11]. In 1996, considering the limitation in uptake of chemotherapy drugs by brain tumors, Halmos and colleagues synthesized Chlorambucilglucose derivative which increased the brain tumor uptake of this drug [29]. In 2004, scientists synthesized amidine analogs of Chlorambucil and assessed their toxicity on breast cancer cells and on topoisomerase I and II inhibitory effects. The investigation showed that these compounds with Chlorambucil were more effective than Chlorambucil alone [12]. In 2008, fluorodeoxyglucose-coupled Chlorambucil derivatives were synthesized, and their toxicity on human normal and tumor cell lines were assessed in vitro. The results of these studies indicated the high effectiveness of the conjugates such as Chlorambucil-flurodoxy hybrid compare to the non conjugate drugs [14].

In 2010, the new analogs of D- and L-tyrosine-Chlorambucil were synthesized, and used as anticancer drugs on breast cancer MCF7 cell line. These analogs had more anticancer actions compared to Chlorambucil [6].

In 2010, the hybrid of estradiol-Chlorambucil was used for chemotherapy in breast cancer, and it was shown they were more effective than Chlorambucil [15].

Considering the expression of Folate Receptors (FRS) on the surface of malignant tumor cells, in 2011, scientists synthesized two new folate conjugates of Chlorambucil. According to the biologic assessment on Leukemia cell line, increased anticancer activity of the conjugates were shown compared to non conjugate Chlorambucil [16].

Based on these research papers and analyzing previous studies, it was concluded that the synthesized conjugates of Chlorambucil were more effective than Chlorambucil alone.

Based on these research documents about synthesis of Chlorambucil conjugate, and the analysis of binding methods, it was concluded that the binding of Chlorambucil to the amino acids occurs at their carboxyl side and not the chlor area. The chlor area is an important factor in killing cells via alkylation.

In 1998, a study was performed in relation to this issue, and several conjugates of Chlorambucil-Albumin were synthesized; the binding site of Albumin to Chlorambucil was different in each hybrid. The killing effects of them were assessed separately on cancerous cells and the final conclusion was the binding of Chlorambucil to Albumin from its carboxyl group increases its effect compare to the other conjugate [30].

Also in 1998, an investigation on the synthesis of ChlorambucilTransferin was done, and the results were similar to the ChlorambucilAlbumin investigation, i.e. the binding of Chlorambucil to Transferin from the carboxyl side of the conjugate showed the same activity and in some cases more activity on the cancerous cells [31]

The carboxyl side in Chlorambucil is pharmacokinetically active but not dynamic. Drugs enter the body from the carboxyl site, complete its path and then leave the body via this side. Therefore the manipulation and binding of the amino acid at the carboxyl area will only affect its absorption and half life, but it will not inhibit the drug's effectiveness.

Finally, it can be concluded that the Chlorambucil-Methionine conjugate is a new compound that due to its Methionine and many nitrogen, is highly absorbable by the cells. Chlorambucil-Methionine conjugate selectively targets most of the cancerous cells which have a high metabolism and absorb more amino compounds. Also due to the $\mathrm{ADH}$ linker which binds Methionine to Chlorambucil its spatial configuration complication is reduced and the entrance of the conjugate into the cells is facilitated. Chlorambucil-Methionine conjugate's killing effect is greater with less toxicity on MCF-7 cell line compared to Chlorambucil.

\section{Acknowledgement}

Special thanks are given Pasteur Institute of Iran, Tehran, Iran, for the financial supports of this research (Grant No.1390-01-40-1566, Contract No. 596).

\section{References}

1. Tfayli A, Temraz S, Abou Mrad R, Shamseddine A (2010) Breast cancer in lowand middle-income countries: an emerging and challenging epidemic. $\mathrm{J}$ Oncol.

2. Elgaili EM, Abuidris DO, Rahman M, Michalek AM, Mohammed SI (2010) Breast cancer burden in central Sudan. Int J Womens Health 2: 77-82.

3. Chan VTC, Yeo W (2011) Antiemetic therapy options for chemotherapyinduced nausea and vomiting in breast cancer patients. J Breast Cancer Targe Therapy 3: 151-160.

4. Roché H, Vahdat LT (2011) Treatment of metastatic breast cancer: second line and beyond. Ann Oncol 22: 1000-1010.

5. Tot T (2011) Breast Cancer: A Lobar Disease. Springer. 
Citation: Omoomi FD, Siadat SD, Nourmohammadi Z, Tabasi MA, Pourhoseini S, et al. (2013) Molecular Chlorambucil-Methionine Conjugate: Novel Anti-cancer Agent against Breast MCF-7 Cell Model. J Cancer Sci Ther 5: 075-084. doi:10.4172/1948-5956.1000188

6. Descôteaux C, Leblanc V, Brasseur K, Gupta A, Asselin É, et al. (2010) Synthesis of $\mathrm{D}$ - and L-tyrosine-chlorambucil analogs active against breast cancer cell lines. Bioorg Med Chem Lett 20: 7388-7392.

7. Torchilin VP (2006) Delivery of protein and peptide drugs in cancer. Imperial College Press.

8. Palmer AJ, Ghani RA, Kaur N, Phanstiel O, Wallace HM (2009) A putrescineanthracene conjugate: a paradigm for selective drug delivery. Biochem $\mathrm{J} 424$ $431-438$

9. Yoon JH, Kim IJ, Kim H, Kim HJ, Jeong MJ, et al. (2005) Amino acid transport system $L$ is differently expressed in human normal oral keratinocytes and human oral cancer cells. Cancer Lett 222: 237-245.

10. Tan Y, Xu M, Tan X, Tan X, Wang X, et al. (1997) Overexpression and largescale production of recombinant L-methionine-alpha-deamino-gammamercaptomethane-lyase for novel anticancer therapy. Protein Expr Purif 9: 233-245.

11. Verschoyle RD, Carthew P, Holley JL, Cullis P, Cohen GM (1994) The comparative toxicity of chlorambucil and chlorambucil-spermidine conjugate to $\mathrm{BALB} / \mathrm{c}$ mice. Cancer Lett 85: 217-222.

12. Bielawska A, Bielawski K, Muszyńska A (2004) Synthesis and biologica evaluation of new cyclic amidine analogs of chlorambucil. IL Farmaco 59: 111117.

13. Salmelin C, Hovinen J, Vilpo J (2000) Polymyxin permeabilization as a too to investigate cytotoxicity of therapeutic aromatic alkylators in DNA repairdeficient Escherichia coli strains. Mutat Res 467: 129-138.

14. Reux B, Weber V, Galmier M, Borel M, Madesclaire M, et al. (2008) Synthesis and cytotoxic properties of new fluorodeoxyglucose-coupled chlorambucil derivatives. Bioorg Med Chem 16: 5004-5020.

15. Gupta A, Saha P, Descôteaux C, Leblanc, Asselin É, et al. (2010) Design, synthesis and biological evaluation of estradiol-chlorambucil hybrids as anticancer agents. Bioorganic \& Medicinal chemistry letters. 20: 1614-1618.

16. Guaragna A, Chiaviello A, Paolella C, D'Alonzo D, Palumbo G, et al. (2011) Synthesis and Evaluation of Folate-Based Chlorambucil Delivery Systems for Tumor-Targeted Chemotherapy. Bioconjug Chem 23: 84-96.

17. Karp G (2010) Cell and Molecular Biology: Concepts and Experiments. (6th edn), John Wiley \& Sons, Inc.
18. Teraoka I (2002) Polymer Solutions: An Introduction to Physical Properties. John Wiley \& Sons.

19. Montaudo G, Lattimer RP (2002) Mass spectrometry of polymers. CRC Press.

20. Langdon SP (2004) Cancer Cell Culture: Methods and protocols. Humana Press, Totowa, New Jersey.

21. Davis JM (1994) Basic Cell Culture: A Practical Approach. IRL Press at Oxford University Press.

22. Mather JP, Roberts PE (1998) Introduction to Cell and Tissue Culture: Theory and Technique. Plenum Press, New York and London.

23. Masters JRW (2000) Animal Cell Culture: A Practical Approach. (3rd edn) Oxford University Press.

24. Costa LG, Hodgson E, Lawrence DA, Reed DJ, Greenlee WF (2005) Current protocols in Toxicology. John Wiley \& Sons.

25. Kainthan RK, Hester SR, Levin E, Devive DV, Brooks DE (2007) In virto biological evaluation of high molecular weight hyperbranched polyglycerols. Biomaterials 28: 4581-4590.

26. Iwasaki Y, ljuin M, Mikami A, Nakabayashi N, Ishihara K (1999) Behavior of blood cells in contact with water-soluble phospholipid polymer. J Biomed Mate Res 46: 360-367.

27. Buchrach U (2004) Polyamines and cancer: Minireview article. Amino Acids 26: 307-309

28. Holley JL, Mather A, Wheelhouse RT, Cullis PM, Hartley JA, et al. (1992) Targeting of tumor cells and DNA by a chlorambucil-spermidine conjugate. Cancer Res 52: 4190-4195.

29. Halmos T, Santarromana M, Antonakis K, Scherman D (1996) Synthesis of glucose-chlorambucil derivatives and their recognition by the human GLUT1 glucose transporter. Eur J Pharmacol 318: 477-484.

30. Kratz F, Beyer U, Roth T, Schütte MT, Unold A, et al. (1998) Albumin conjugates of the anticancer drug chlorambucil: synthesis, characterization, and in vitro efficacy. Arch Pharm (Weinheim) 331: 47-53.

31. Beyer U, Roth T, Schumacher P, Maier G, Unold A, et al. (1998) Synthesis and in vitro efficacy of transferrin conjugates of the anticancer drug chlorambucil. $J$ Med Chem 41: 2701-2708 